\title{
Ocular Morbidity Among Leprosy Patients at a Leprosy Centre
}

\section{Sabina Shrestha', Chunu Shrestha', Sushan Man Shrestha ${ }^{2}$, Aparajita Manoranjan ${ }^{1}$ and Arun Prasad Dhungana ${ }^{1}$}

1Department of Ophthalmology, Nepal Eye Hospital, Tripureshwor, Kathmandu, Nepal

2Department of Ophthalmology, Tribhuwan University Teaching Hospital, Maharajgunj, Kathmandu, Nepal

\begin{abstract}
Introduction: Leprosy is one of the dreaded communicable disease due to its profound morbidity. In earlier days in Nepal, a different settlement was designated for leprosy patient and their families. Khokana of Lalitpur district of Nepal is one of them. The study was conducted to determine ocular morbidity among leprosy patients who had completed multi drug therapy.

Methods: It was descriptive, quantitative and cross sectional study conducted at Khokana Leprosy Centre in Lalitpur district of Nepal. Leprosy patients who had completed multi drug therapy and consenting for the study were enrolled. Convenience sampling was done and the sample size was 70. After detail ophthalmic evaluation, socio-demographic profile of the participants and their ocular morbidities were documented and analysed.

Results: Major findings were superciliary madarosis (78.57\%), ciliary madarosis $(61.4 \%)$, different grades of cataract (67.10\% right eye and $60 \%$ left eye), pseudophakia (30\% right eye and $37.10 \%$ left eye), tylosis $(44.3 \%)$, corneal hypoesthesia (10\% unilaterally and $15.7 \%$ bilaterally) and dry eye (10\%). Entropion was present in $2.9 \%$ both unilaterally and bilaterally. Ectropion was present in $5.7 \%$ unilaterally and $10 \%$ bilaterally. Trichiasis was present in $1.4 \%$ unilaterally and $2.9 \%$ bilaterally. Similarly, eyelid nodule was present in $7.1 \%$ unilaterally and $1.4 \%$ bilaterally. Incomplete closure of the lids was present in $8.6 \%$ unilaterally and $2.9 \%$ bilaterally. Exposure keratitis was present in $7.1 \%$ unilaterally and $1.4 \%$ bilaterally, corneal opacity in $2.9 \%$ unilaterally and $1.4 \%$ bilaterally and corneal perforation in $2.9 \%$ unilaterally. Chronic iridocyclitis was present in $2.9 \%$ cases. Retinal pearls were seen in $2.86 \%$ of cases. According to WHO criteria of blindness, $2.9 \%$ patients were blind in the present study. 14 persons were unilaterally blind and among them, two had severe visual impairment in the other eye, eight had other eye moderate visual impairment and four had other eye mild visual impairment.

Conclusions: Lid abnormalities, corneal abnormalities and cataract were the commonly encountered ocular morbidities among treated leprosy patients.

Keywords: Leprosy; ocular involvement; potentially sight threatening lesions
\end{abstract}

Correspondence: Sabina Shrestha, Department of Ophthalmology, Nepal Eye Hospital, Tripureshwor, Kathmandu, Nepal. Email: sabina_drs@hotmail.com

DOI: http://dx.doi.org/10.3126/mjsbh.v17i2.18484

Submitted on: $2017-10-25$

Accepted on: 2018-06-4 


\section{INTRODUCTION}

Leprosy is a chronic granulomatous infective disease caused by Mycobacterium leprae primarily affecting peripheral nerves and skin. However, it also affects other structures like eyes, mucosa of respiratory tract, muscles, bones, reticuloendothelial system and the testes. ${ }^{1}$ Among the multibacillary and paucibacillary categories of leprosy, ocular involvement is especially high in multibacillary type of leprosy. ${ }^{2-4}$ Leprosy affects 10 million to 12 million people worldwide, $3 \%$ to $7 \%$ of whom are blind. ${ }^{5}$ Ocular involvement is frequent with estimates ranging from $6 \%$ to $100 \%{ }^{6}$

Comprehensive ocular evaluations of leprosy patients show that uveitis occur in about 7\%.5,7 Rarely, choroiditis, pars planitis and uveal effusion associated with overlying scleral inflammation have been reported. ${ }^{8}$ Lagophthalmos, uveitis, corneal hyposthesia, secondary glaucoma and cataract are causes of blindness in leprosy patients. 3,4

The prevalence of blindness due to leprosy has been variously estimated as being $4.7 \%$ in India, ${ }^{9}$ $1.6 \%$ in Nigeria, ${ }^{10} 1.3 \%$ in China, ${ }^{11} 1.2 \%$ in Nepal ${ }^{12}$ and $0.6 \%$ in Uganda. ${ }^{13}$ A selected groups of leprosy affected individuals in hospitals or leprosaria are known to have a high frequency of multiple complications. $9,14,15$

\section{METHODS}

It was a descriptive, quantitative cross sectional study was done at leprosy centre of Khokana of Lalitpur district of Nepal. The study was conducted by Professional Support Service Nepal (PSSN). Leprosy patients who had completed multi drug therapy for leprosy and consenting for the study were enrolled. Convenience sampling was done and the sample size was 70 .

Detailed ophthalmic examination was carried out by ophthalmologists, optometrist, orthoptist and ophthalmic assistants. Ocular examination was done with the help of a slit lamp. Dilated fundus examination was done in all the cases with indirect ophthalmoscope. Distant visual acuity was tested using Snellen's acuity chart and best corrected visual acuity was assessed by optometrist. They were examined for lid changes like madarosis, trichiasis, tylosis, entropion, ectropion, eyelid nodules and atrophy of tarsal plate pretarsal muscles. The participants were also examined for lagophthalmos, dry eyes, dacryocystitis and lepromatous nodules of the conjunctiva. Similarly, cornea was examined for superficial punctate keratitis, interstitial keratitis, hypothesia of cornea, pannus, neurotrophic keratitis, neuropararalytic keratitis, corneal melting and perforation. Participants were also examined for episcleritis, scleritis, iridocyclitis, cataract, chorioretinitis, retinal pearls, endophthalmitis and panophthalmitis. Intraocular pressure was also measured in all the cases with Schiotz tonometer.

The data were recorded in specially designed performa and reviewed for recording errors. Then they were recorded in Excel and transferred into SPSS version 20 for analysis. The analysis was done using the same statistical software.

\section{RESULTS}

70 participants who had completed multidrug therapy for leprosy were examined to study ocular involvement in leprosy. Among them, 22.85\% had associated hypertension and $8.57 \%$ had associated diabetes mellitus. Age ranged from 30 to 98 years and mean age was 66.5 years with standard deviation of \pm 13.4 years. Regarding gender distribution, $39 \%$ were male and $61 \%$ were female.

In the present study, 14 were unilaterally blind and among them, two had other eye severe visual impairment, eight had other eye moderate visual impairment and four had other eye mild visual 
Table 1. Distribution of visual acuity

\begin{tabular}{|l|r|r|r|r|}
\hline $\begin{array}{l}\text { Group } \\
\text { visual } \\
\text { acuity }\end{array}$ & $\begin{array}{c}\text { Frequency } \\
\text { (RE) }\end{array}$ & $\begin{array}{r}\% \\
\text { (RE) }\end{array}$ & $\begin{array}{r}\text { Frequency } \\
\text { (LE) }\end{array}$ & $\begin{array}{c}\% \\
\text { (LE) }\end{array}$ \\
\hline $\begin{array}{l}\mathbf{6} / \mathbf{6} \text { to } \\
\mathbf{6} / \mathbf{1 8}\end{array}$ & 32 & 45.7 & 28 & 40 \\
\hline $\begin{array}{l}\mathbf{6} / \mathbf{2 4} \text { to } \\
\mathbf{6} / \mathbf{6 0}\end{array}$ & 31 & 44.3 & 29 & 41.4 \\
\hline $\begin{array}{l}\mathbf{5} / 60 \text { to } \\
\mathbf{3} / \mathbf{6 0}\end{array}$ & 2 & 2.9 & 4 & 5.7 \\
\hline$<\mathbf{3} / \mathbf{6 0}$ & 5 & 7.1 & 9 & 12.9 \\
\hline
\end{tabular}

impairment. Bilateral superciliary madarosis was present $78.6 \%$, ciliary madarosis was in $61.4 \%$ and tylosis in $44.3 \%$. Trichiasis was present in $1.4 \%$ unilaterally and $2.9 \%$ bilaterally. Entropion was present $2.9 \%$ both unilaterally and bilaterally. Ectropion was present in $5.7 \%$ unilaterally and $10 \%$ bilaterally. Similarly, eyelid nodule was present in $7.1 \%$ unilaterally and $1.4 \%$ bilaterally. Incomplete closure of the lids was present in $8.6 \%$ unilaterally and $2.9 \%$ bilaterally.

Corneal changes like corneal hypothesia was present in $10 \%$ unilaterally and $15.7 \%$ bilaterally, exposure keratitis in $7.1 \%$ unilaterally and $1.4 \%$ bilaterally, corneal opacity in $2.9 \%$ unilaterally and $1.4 \%$ bilaterally and corneal perforation in $2.9 \%$ unilaterally.

Apart from the lid and corneal changes, episcleritis was seen in $4.3 \%$ unilaterally, dry eye in $10 \%$, chronic iridocyclitis in $2.86 \%$ unilaterally. Similarly, different grades of cataract was found in $67.1 \%$ right eye and $60 \%$ left eye and pseudophakia in $30 \%$ right eye and $37.1 \%$ left eye. Punctal occlusion was found in $5.71 \%$ unilaterally and chronic dacryocystitis in $1.4 \%$ unilaterally. Tarsorraphy was done in $5.71 \%$ unilaterally for lagophthalmos. Even retinal pearls were seen in $2.86 \%$ unilaterally.
Table 2. Distribution of visual status

\begin{tabular}{|l|r|r|}
\hline Visual status & Frequency & $\%$ \\
\hline $\begin{array}{l}\text { Bilateral no visual } \\
\text { impairment }\end{array}$ & 2 & $2.9 \%$ \\
\hline $\begin{array}{l}\text { Better eye no visual } \\
\text { impairment }\end{array}$ & 2 & $2.9 \%$ \\
\hline $\begin{array}{l}\text { Bilateral mild visual } \\
\text { impairment }\end{array}$ & 18 & $25.7 \%$ \\
\hline $\begin{array}{l}\text { Better eye mild visual } \\
\text { impairment }\end{array}$ & 16 & $22.9 \%$ \\
\hline $\begin{array}{l}\text { Bilateral moderate visual } \\
\text { impairment }\end{array}$ & 19 & $27.1 \%$ \\
\hline $\begin{array}{l}\text { Better eye moderate } \\
\text { visual impairment }\end{array}$ & 11 & $15.7 \%$ \\
\hline $\begin{array}{l}\text { Better eye severe visual } \\
\text { impairment }\end{array}$ & 2 & $2.9 \%$ \\
\hline
\end{tabular}

\section{DISCUSSION}

Although leprosy was declared globally eliminated in 2001, pockets of high endemicity still remain, primarily in a few developing countries according to World Health Organisation. ${ }^{16}$

The three major causes of blindness due to leprosy are corneal opacity, iridocyclitis and its sequelae and cataract. To prevent impairment of vision and blindness, ocular involvement must be detected in the early stages. In a study by Kasugur et al., ocular changes are seen in all types of leprosy and ocular involvement was seen in $58 \%$ of the patients. ${ }^{17}$

According to World Health Organisation criteria of blindness, $2.9 \%$ patients were blind in the present study similar to the study by Thompson et al. in which $2.9 \%$ subjects were blind and $20.7 \%$ had moderate visual impairment. ${ }^{18}$ However, in a study in non-institutionalised community in United States showed a relatively low frequency of visual impairment attributable to leprosy. 19

More than one lesion were seen among the participants with ocular involvement. Potentially sight threatening lesions were lagophthalmos 
leading to exposure keratopathy, corneal opacity and cataract. However, in the present study, the participants with cataract were in the age group 40 to 60 years and may be due to age factor also.

In a study by Eballe et al. in 11 leper villages of Southern Cameroon, visual handicap was present in $47.2 \%$ of the population with $19 \%$ of bilateral blindness, $15 \%$ of unilateral blindness and $13.2 \%$ of low vision. ${ }^{20}$ In a study by Mpyet $\mathrm{C}$ and Solomon AW, $37 \%$ of the ocular lesions were leprosy related and was potentially sight threatening. Cataract was the commonest cause of blindness and other causes were non-trachomatous corneal opacity and trachoma. ${ }^{21}$ Over one in five leprosy patients had a potentially sight-threatening ocular complication in a study by Malik et al. ${ }^{22}$

Dry eye is a condition characterised by ocular surface disorder resulting from any of the conditions like decreasing tear production or increasing tear film evaporation. In the present study, dry eye was present in $10 \%$ of the participants. A study conducted by Hodges et al. suggested that a patient with leprosy is at risk of developing keratoconjunctivitis sicca and the aqueous layer of the tear film may be deficient due to reduced secretion of tear film from the accessory lacrimal glands of the conjunctiva. It could also be due to a diseased afferent arc to the lacrimal gland. ${ }^{23}$ A study by Passeroti et al. showed that low tear production is the main cause of dry eye in leprosy. ${ }^{24}$ In a study by Koshy et al., the quality of tear produced is not affected but the tear film seemed to be unstable in many leprosy patients. Leprosy patients with lagophthalmos and decreased corneal sensation showed a lower value of tear break up time. ${ }^{25}$

Singh $L$ et al. has also recommended screening of ocular disability to be incorporated as a routine protocol in people affected with leprosy for reducing the severity of ocular disability. In their study, the most common cause for ocular World Health Organisation grade 2 disability was corneal involvement (14.23\%). ${ }^{26}$

In ocular impairments in an impairment survey of leprosy- affected persons in Nepal, the most common ocular impairment was poor vision followed by lagophthalmos and insensitive cornea. ${ }^{27}$ Although retinal involvement is very rare in leprosy, $2.86 \%$ had retinal pearls in the present study.

According to Grzybowski A et al., about $10 \%$ to $15 \%$ of leprosy patients suffer from severe ocular symptoms and blindness occurs in about $5 \%$ of patients. Apart from that, completion of multidrug therapy does not guarantee the withholding of other complications. ${ }^{28}$ In the present study also, although there is the completion of treatment, ocular complications were still present.

Among 186 treated leprosy patients who had received Multi drug treatment at least 12 to 24 month period, $18.27 \%$ patients had moderate to severe visual impairment in a study by Abdul Selam Ghayas et al. ${ }^{29}$ In our study, bilateral moderate visual impairment was present in $27.1 \%$ and better eye moderate visual impairment in $15.7 \%$. Similarly, better eye severe visual impairment was present in $2.9 \%$.

\section{CONCLUSIONS}

Lid abnormalities, corneal abnormalities and cataract were the commonly encountered ocular morbidities among leprosy patients

\section{ACKNOWLEDGEMENT}

Authors would like to thank Professional Support Service Nepal for supporting the study and Leprosy centre Khokana for consenting for the study. 
To cite this article: Shrestha S, Shrestha C, Shrestha SM, Manoranjan A, DhunganaAP. Ocular morbidity among leprosy patients at a leprosy centre. MJSBH. 2018;17(2):44-50.

Conflict of Interest: None declared

\section{REFERENCES}

1. Jopling W H, Mc Dougall AC. Handbook of Leprosy. 4thed. New Delhi, India: CBS Publ; 1992:21-50.

2. Monteiro LG, Campos WR, Orefice F, Grossi MA. Study of ocular changes in leprosy patients. Indian J Lepr. 1998;70:197-202.

PMID:9724855

3. Nsosu SN, Nwosu MC. Ocular findings in leprosy patients in Nigeria. East Afr Med J. 1994;441-4. PMID:7828497

4. Malla O K, Brandt F, Anten JG. Ocular findings in leprosy patients in an institution in Nepal (Khokana). Br J Ophthalmol 1981;65:226-30.

DOI: https://doi.org/10.1136/bjo.65.4.226

5. Dana MR, Hochman MA, Viana MA, Hill CH, Sugar J. Ocular manifestations of leprosy in a noninstitutionalized community in the United States. Archives of Ophthalmology. 1994 May;112(5): $626-9$.

DOI: https://doi.org/10.1001/archopht.1994.01090170070025

6. Sugar J, Hill C. Leprosy in eye and skin diseases. Philadelphia: Lippincott-Raven; 1996:543-50.

7. Sekhar GC, Vance G, Otton S, Kumar SV, Stanley JN, Rao GN. Ocular manifestations of Hansen's disease. Documenta ophthalmologica. 1994 Mar;87(3):211-21.

DOI: https://doi.org/10.1007/BF01203851

8. Schwab IR, Ostler HB, Dawson CR. Hansen's disease of the eye (ocular leprosy). Duane's clinical ophthalmology. Vol 5. Philadelphia: JB Lippincott; 2000.

9. Fytche TJ. Residual sight threatening lesions in leprosy patients completing multidrug therapy and sulphone monotherapy. Lepr Rev. 1991;62:35-43.

DOI: https://doi.org/10.5935/0305-7518.19910005

10. Malu KN, Malu AO. Blindness in leprosy patients of Kaduna state, Northern Nigeria. Trop Doct. 1995;25:181-3.

DOI: https://doi.org/10.1177/004947559502500413

11. Yang J, Jian D, Hu L, Liu J, Wang K. Blindness and low vision in leprosy patients in Sichuan Province, China. Indian journal of leprosy. 1998;70(1):139-43.

PMID:9598417

12. Knuuttila JP, van Brakel WH, Anderson AM. Ocular impairments in an impairment survey of leprosyaffected persons in Nepal. Ind J Lpr. 1998;70:93-6. 
PMID:9598409

13. Waddell KM, Saunderson PR. Is leprosy blindness avoidable? The effect of disease type, duration and treatment on eye damage from leprosy in Uganda. Br J Ophthalmol. 1995;79:250-6.

DOI: https://doi.org/10.1136/bjo.79.3.250

14. Mvogo CE, Bella-Hiag AL, Ellong A, Achu JH, Nkeng PF. Ocular complications of leprosy in Cameroon. Acta Ophthalmologica Scandinavica. 2001 Feb;79(1):31-3.

DOI: https://doi.org/10.1034/j.1600-0420.2001.079001031.x

15. Courtright PD. Defining the magnitude of ocular complications of leprosy: problems of methodology. Int J Lepr Other Mycobact Dis. 1988; 56: 566-573.

PMID:3221113

16. World Health Organization. Leprosy Fact Sheet N101.

Available at http://www.who.int/mediacentre/factsheets/fs101/en/.Accessed:January 212015.

17. Kausugar SR, Kasugar MS, Gauri K. A clinical study of ocular manifestations in leprosy. Journal of Evolution of Medical and Dental Sciences. 2013 Sept;36(2):6816-28.

18. Thompson KJ, Allardice GM, Babu GR, Roberts H, Kerketta W, Kerketta A. Patterns of ocular morbidity and blindness in leprosy-a three centre study in Eastern India. Leprosy review. 2006 Jun 1;77(2):130..

19. Dana MR, Hochman MA, Viana MA, Hill CH, Sugar J. Ocular manifestations of leprosy in a noninstitutionalised community in the United States. Archives of Ophthalmology. 1994 May;112(5):626-9. DOI: https://doi.org/10.1001/archopht.1994.01090170070025

20. Eballe' AO, Owono D, BookAU, Bella AL, Mvoqo CE, Mba N. Prevalence and etiologies of visual handicaps in leprosy patients in the south of Cameroon. Clin Ophthalmol. 2009;3:195-8.

DOI: https://doi.org/10.2147/OPTH.S4495

21. Mpyet C, Solomon AW. Prevalence and causes of blindness and low vision in leprosy villages of north eastern Nigeria. Br J Ophthalmol. 2005 Apr;89(4):417-9.

DOI: https://doi.org/10.1136/bjo.2004.048777

22. Malik AN, Morris RW, Ffytche TJ. The prevalence of ocular complications in leprosy patients seen in the United Kingdom over a period of 21 years. Eye (Lond). 2011.25(6):740-5.

DOI: https://doi.org/10.1038/eye.2011.43

23. Hedges EJ, Ostler HB, Courtright P, Gelber RH. Keratoconjunctivitis sicca in leprosy.Lepr. Rev. 1987;58.413-7.

24. Passeroti S, Salotti R, Vieth H. Assessment and treatment of the dry eye in leprosy. Indian J. Lepr. $1998 ; 103-8$.

25. Koshy S, Daniel E, Kurian N, Yovan P. Pathogenesis of dry eye in leprosy and tear functions. Significance. 2001;6:63..

26. Singh L, Malhotra R, Bundela RK, Garg P, Dhillon KS, Chawla S, et al. Ocular disability - WHO grade 2 in persons affected with leprosy. Indian J Lepr. 2014;86(1):1-6. 
27. Knuttila JP, Barkel WH, Anderson AM. Ocular Impairments in an Impairment Survey of Leprosy Affected Persons in Nepal. Indian J Lepr. 1998;70(1):93-6.

PMID:9598409

28. Grybowski A, Nita M, Virmond M. The completion of multidrug treatment does not guarantee the withholding of ocular complications. Clin Dermatol. 2015;33(1):79-89.

29. Ghayas AS, Saaiq M. Clinical observations in leprosy cases treated at Diamer district of Gilgit-Baltistan, Pakistan. The Journal of the Pakistan Medical Association. 2013 Nov;63(11):1415-7.

PMID:24392530 